\title{
A cockscomb-like aneurysm of the right coronary artery after bare metal stent implantation
}

\author{
Mehmet Emin Kalkan, Göksel Açar, Mehmet Mustafa Tabakcı, Serdar Demir, Müslüm Sahin, \\ Mustafa Akçakoyun \\ Department of Cardiology, Kartal Kosuyolu High Specialty Education and Research Hospital, Istanbul, Turkey \\ Postep Kardiol Inter 2014; 10, 1 (35): 50-52 \\ DOI: $10.5114 /$ pwki.2014.41470
}

\begin{abstract}
A bstract
Coronary artery aneurysm (CAA) formation is an uncommon but potentially life-threatening event after coronary balloon angioplasty or stent implantation. In this report, we present a case of a patient who had a cockscomb-like aneurysm after bare metal stent implantation which was successfully treated with a coronary graft stent.
\end{abstract}

Key words: coronary artery aneurysm, bare metal stent.

\section{Introduction}

Coronary artery aneurysm (CAA) formation is an uncommon but potentially life-threatening event after coronary stent implantation. The development of CAA was frequently reported after drug-eluting stent (DES) implantation. Drug-eluting stents may affect the normal healing process of the vessel wall and the remodeling process may lead to CAA. However, this complication may also be seen with the use of bare metal stents (BMS), which is really rare.

In this report, we present a case of a patient who had a cockscomb-like aneurysm at 1 year after BMS implantation which was successfully treated with a coronary graft stent.

\section{Case report}

A 69-year-old female patient with non-ST elevation myocardial infarction was admitted to our hospital, a year ago. Coronary angiography was performed, revealing the culprit lesion in the proximal segment of the right coronary artery (Figure $1 \mathrm{~A}$ ). A BMS with the size of $2.75 \mathrm{~mm}$ $\times 18 \mathrm{~mm}$ was directly implanted, successfully (Figure $1 \mathrm{~B}$ ). There was no complication during the first procedure. One year later, she was admitted to our emergency care unit with chest pain. In ECG, T wave abnormalities were seen in the inferior derivations (DII, DIII and aVF). Coronary an- giography was performed, showing a severe restenosis and cockscomb-like aneurysm within the mid segment of the BMS in the right coronary artery (Figures $2 \mathrm{~A}$ and $2 \mathrm{~B}$ ). The coronary aneurysm was treated by directly stenting with a coronary graft stent (CGS) (Figures $2 \mathrm{C}$ ). The cockscomb-like aneurysm was fully covered with a CGS, $2.75 \mathrm{~mm}$ $\times 24 \mathrm{~mm}$ in size. Subsequently, adjunctive balloon dilatation with a $3.0 \mathrm{~mm} \times 12 \mathrm{~mm}$ non-compliant balloon was performed. After the successful procedure, the coronary aneurysm was no longer detected (Figure $2 \mathrm{C}$ ).

\section{Discussion}

Coronary artery aneurysms can cause coronary ischemia as a result of thrombosis from motionless blood flow, distal coronary embolism or vasospasm. Furthermore, life-threatening events, even sudden death, can be seen due to the rupture of the CAA. Intracoronary imaging with optical coherence tomography and/or intravascular ultrasound can provide insight into aneurysm formation following coronary artery stenting [1]. It has been shown that CGS may be associated with a higher incidence of restenosis and thrombosis [2]. However, covering the CAA with CGS implantation can successfully seal the aneurysm and serves a safe curative solution for the CAA $[3,4]$. Nevertheless, it is difficult to standardize selection of the ideal therapy for this entity.

\section{Corresponding author:}

Göksel Açar MD, Department of Cardiology, Kartal Kosuyolu High Specialty Education and Research Hospital,

Denizer cd. Cevizli kavsag No: 2, 34846 Istanbul, Turkey, phone: +90 (216) 500 1500, e-mail: gokselacar81@hotmail.com

Received: 15.03.2013, accepted: 23.10.2013. 

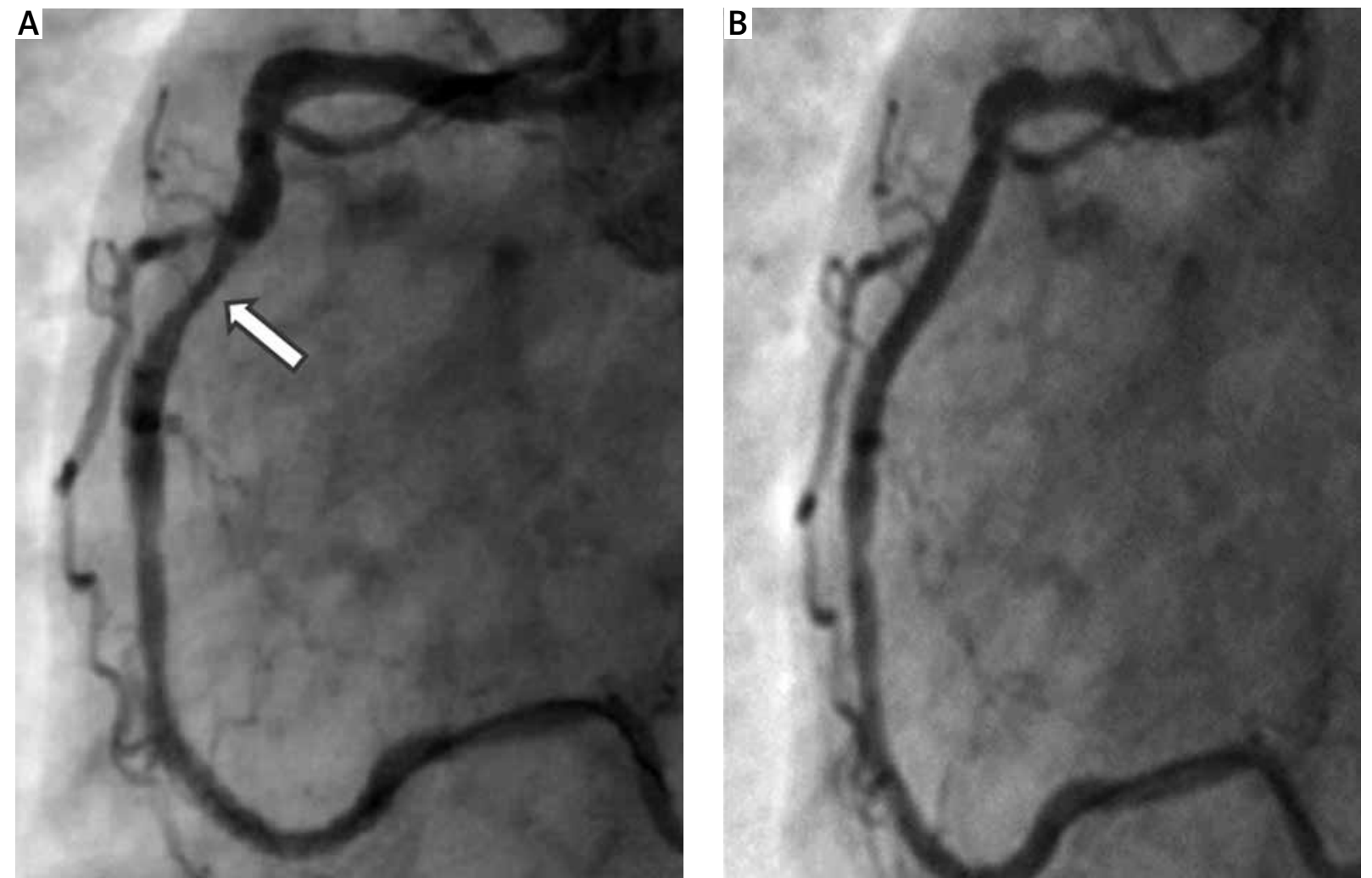

Figure 1. Coronary angiography was showed culprit lesion in the proximal segment of the right coronary artery (A), and after the successful bare-metal stent implantation (B)
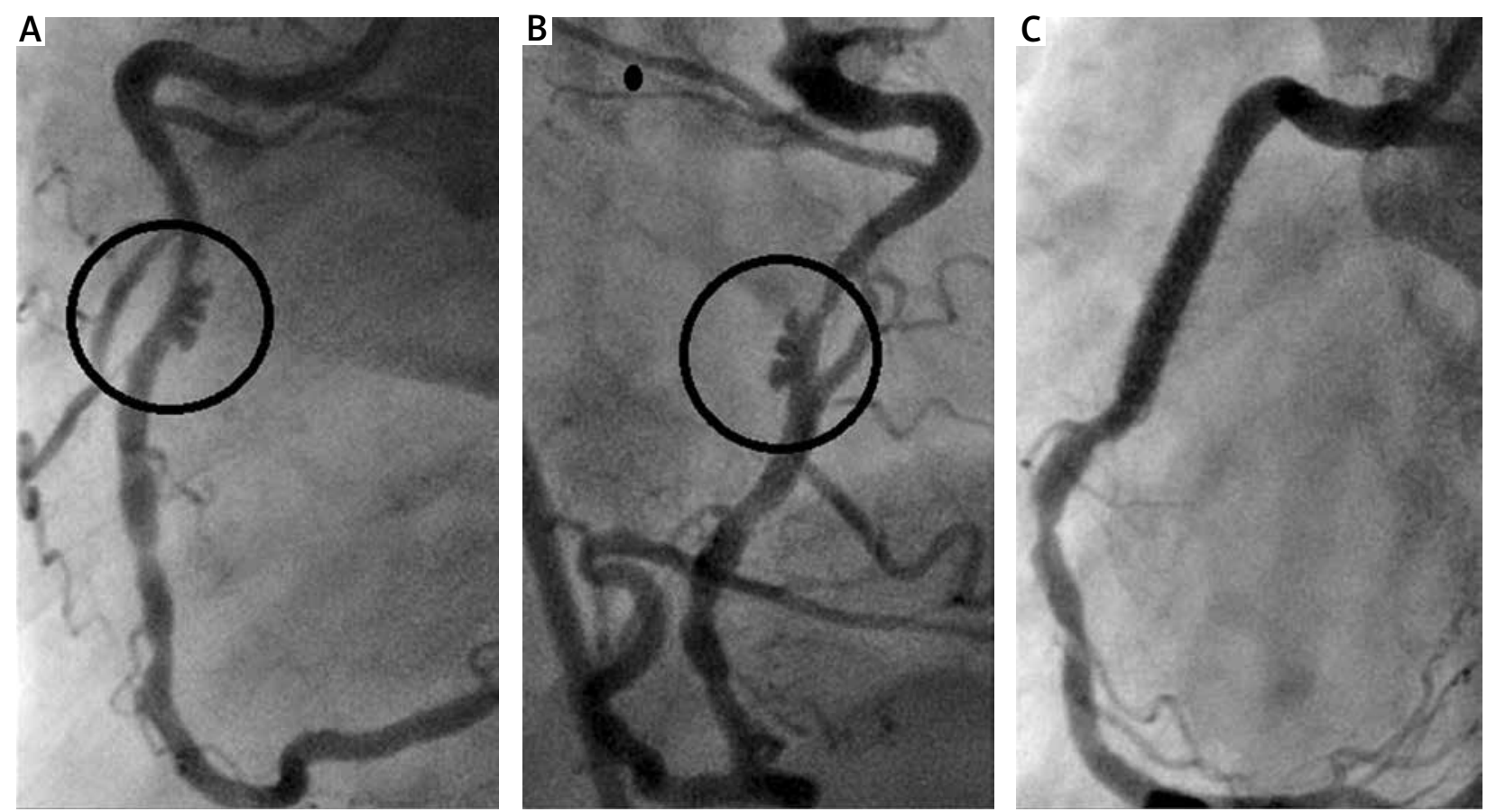

Figure 2. Coronary angiographic poses showing a cockscomb-like aneurysm involving the within the mid segment of the bare-metal stent in the right coronary artery $(\mathbf{A}, \mathbf{B})$. Coronary angiography showing that there is no any problem, after the successful coronary graft stent implantation (C) 


\section{References}

1. Yoshikawa D, Ishii H, Aoyama Y, et al. Optical coherence tomography images of a coronary artery aneurysm in an infarct-related artery 6 months after bare-metal stent implantation. JACC Cardiovasc Interv 2010; 3: 1300-1302.

2. Schachinger V, Hamm CW, Munzel T, et al. A randomized trial of polytetrafluoroethylenemembrane-covered stents compared with conventional stents in aortocoronary saphenous vein grafts. J Am Coll Cardiol 2003; 42: 1360-1369.

3. Süselbeck T, Haghi D, Borggrefe M, Kaden JJ. Percutaneous treatment of a coronary aneurysm by stent graft and drug-eluting stent implantation: a potential method to reduce stent graft restenosis. J Interv Cardiol 2008; 21: 325-328.

4. Ozden K, Sengül C, Fotbolcu H, Dindar I. A late coronary aneurysm after sirolimus stent implantation which was treated with coronary graft stent. Arch Turk Soc Cardiol 2012; 40: 440-443. 